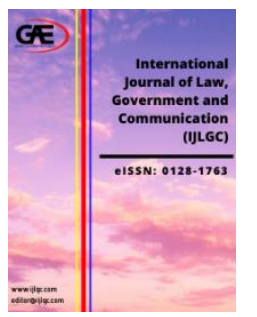

\author{
INTERNATIONAL JOURNAL OF LAW, \\ GOVERNMENT AND COMMUNICATION \\ (IJLGC) \\ www.ijlgc.com
}

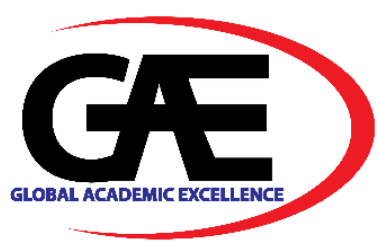

\title{
ETHICAL CONSIDERATIONS FOR COMPULSORY CHILDHOOD VACCINATION IN MALAYSIA
}

\author{
Khairun Nisaa Asari $^{1 *}$, Yuhanif Yusof ${ }^{2}$, Rohizan Halim ${ }^{3}$ \\ 1 School of Law, UUM COLGIS, Malaysia \\ Email: nisaa@unisza.edu.my \\ 2 School of Law, UUM COLGIS, Malaysia \\ Email: yuhanif@uum.edu.my \\ 3 School of Law, UUM COLGIS, Malaysia \\ Email: rohizan@uum.edu.my \\ Corresponding Author
}

\section{Article Info:}

Article history:

Received date: 09.11.2020

Revised date: 15.11 .2020

Accepted date: 10.12 .2020

Published date: 10.03.2021

\section{To cite this document:}

Asari, K. N., Yusof, Y., \& Halim, R. (2021). Ethical Considerations for Compulsory Childhood Vaccination in Malaysia. International Journal of Law, Government and Communication, 6 (22), 197-205.

DOI: $10.35631 /$ IJLGC.6220019.

This work is licensed under $\underline{\mathrm{CC} B Y} \mathbf{4 . 0}$

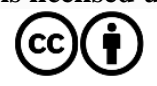

\begin{abstract}
:
Childhood vaccination is an important tool for controlling and eliminating lifethreatening infectious diseases among infants, who are most vulnerable due to their weaker immune systems. Due to this, certain countries resorted to enforcing compulsory childhood vaccination laws. Yet despite the proven effectiveness of childhood vaccination, it is also outweighed by numerous ethical implications. This paper focuses on the discussion of ethical considerations surrounding compulsory childhood vaccination in Malaysia. Focusing on the topic of compulsory vaccination of children, this paper discusses ethical issues related to parental autonomy, medical paternalism, compulsory childhood vaccination, and related legal issues. For the purpose of this article, the vaccination practices as implemented in the United States will be referred. At the end of this article, some recommendations are proposed in relation to the drafting of the legal framework on compulsory childhood vaccination in Malaysia. This article employs a doctrinal analysis and secondary data from academic journals and online databases.
\end{abstract}

Keywords:

Ethical Considerations, Compulsory Vaccination, Childhood Vaccination, Vaccination, Law

\section{Introduction}

The debate on the success of vaccination as prevention of vaccine preventable diseases has been the focus of many researchers. One of the important effects of vaccination is that it creates a phenomenon known as herd immunity. In herd immunity, vaccination gives protection not only to the individual who gets vaccinated, but also gives indirect protection to unvaccinated Copyright $\odot$ GLOBAL ACADEMIC EXCELLENCE (M) SDN BHD - All rights reserved 


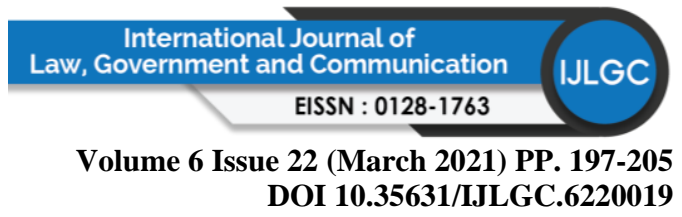

individuals, due to the fact they are surrounded by vaccinated individuals. These unvaccinated individuals, by reason of age or medical contraindications, past allergic reaction to a vaccine, or underlying medical condition depend on herd immunity for protection (Diekima, 2009). Yet despite the tremendous contribution of childhood vaccination, it is disturbing to see the report from the Ministry of Health Malaysia on the rising number of vaccine refusal cases by parents. According to the Ministry of Health Malaysia $(\mathrm{MOH})$, the number of vaccines rejection recorded in royal clinics continued to increase, compared to 637 cases in 2013 to 1,603 cases in 2016. 2018, the Ministry produced six (6) measles deaths in which all cases had no immunization, five (5) diphtheria deaths in which four (4) cases had no immunization, when 22 deaths due to pertussis, in which 19 cases were due to non-immunization (Arumugam, 2019). The issue of compulsory childhood vaccination once again becomes a pressure last year after a polio case has been confirmed in Malaysia, its first after 27 years of being declared polio free (Chung, 2019). Thus in overcoming the problem of infectious diseases and parents refusal to vaccinate their children, the $\mathrm{MOH}$ has made a series of statements voicing out the need for compulsory vaccination law. The latest development was in 2019 where the MOH is setting up task force to draft a proposal on compulsory childhood vaccination, with the aim of making at least 2 out of 12 childhood vaccinations compulsory ("Minister ready", 2019).

However, the compulsory childhood vaccination laws also create numerous ethical issues. It is submitted that before the Malaysian government decides to propose a compulsory childhood vaccination law, these ethical issues must first be looked into. This article discusses the ethical considerations arising out of compulsory childhood vaccination law, if it were to be proposed in Malaysia. For this purpose, the authors referred to the vaccination practices in United States, which has a developed framework on compulsory vaccination. It is observed that currently the discussion on compulsory childhood vaccination law in Malaysia is still lacking. Thus, this research aims to contribute in proposing a legal framework on compulsory childhood vaccination in Malaysia.

This article employs a doctrinal analysis and secondary data from academic journals and online databases. The authors adopted qualitative research method to gather data in writing this paper. The primary data will be collected and analysed. The sources of the data are analysis of decided cases, legislations, policies and guidelines on compulsory vaccination of children and its comparison with other countries. Library research is used to get the reference to the concept of compulsory vaccination based on the text books, journal articles and other relevant materials. Reference is also made through the manuscript materials or brochures available from the health clinics and Ministry of Health Departments. Reference will also be made to the practise of childhood vaccination in the United States.

\section{Medical Paternalism vs Parental Autonomy in Vaccine Decision Making}

From the time when the Hippocratic Oath was formulated, doctors are generally regarded as having a positive duty to do good, thus the medical profession has always been trusted to do what is best for their patients (Jahn Kassim, 2009). The relationship between a doctors and patient resembled that of a child and a parent, which is inherently paternalistic. This paternalistic approach to health care decisions however has undergone a transformation over the years, and the result has been a shift towards the rights of patients' autonomy. Evidence of the shift from paternalism to autonomy can be seen in the matter of informed consent. Such changes include the evolution of the patient-centered model, which identifies the doctor and patient as equals but with different expertise. This model encourages doctors to explore 


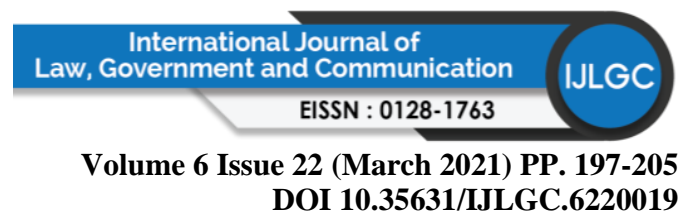

patients' individual needs and priorities because the information they need in order to reach decisions may be influenced by their different beliefs, culture, occupation, or other factors (McCoy, 2008).

Despite the dramatic shift from paternalistic models of doctor-patient interaction towards patient-centered model, one of the most significant examples of the former which still remains is compulsory vaccination laws. Due to the success of vaccination in preventing vaccine preventable diseases, a number of countries have adapted legislations which made childhood vaccination compulsory. These states have relied on certain justifications in mandating childhood vaccination. One of the main justifications is the 'harm principle,' in which coercive state action could be justified when an individual's decision or action places others at risk of harm (Mill, 2010). This principle is further used in the United States as a justification for its compulsory vaccination laws, in the case of Jacobson v. Massachusett (1905). In applying this principle, state and school compulsory vaccination programs are created not only because they provide health benefit to the vaccinated individual, but because they protect other individuals in the community. It is argued that when the decision of a parent places a child at substantial risk of serious harm, it would be up to the state agency to decide whether immunization would be required, considering the best interest of the child. This case has become a legal precedent for compulsory vaccination laws in all fifty states in United States, where the laws made vaccinations compulsory for admission to primary and secondary schools, licensed day care, even adults entering college (Jackson, 1969). These school vaccination laws require children to be vaccinated in accordance with Advisory Committee on Immunization Practices recommendations before attending school. However, all states also allow medical exemptions, whereas some states allow exemptions based on religious beliefs and personal beliefs. Admission may be allowed to children who have not received the necessary vaccinations, on the condition that they have been granted a medical exemption or a personal belief exemption. In case of medical exemption, it will be granted if the children acquired a written statement from a licensed healthcare professional stating exemption of vaccination due to his or her physical condition. Whereas the personal belief exemption is very broadly defined and only requires a statement by the parent or guardian of the pupil stating that such immunization is contrary to his or her beliefs. As for religious beliefs exemption, there is no limit to it, to the extent that exemption is even allowed for belief that the government is conspiring with pharmaceutical companies to maximize profits at the expense of children's health or safety, among others (Baxter, 2014).

Meanwhile, parents' approach to vaccination by making a decision based on parental autonomy places strong emphasis on the freedom, privacy and informed consent of parents in vaccine decision making. Current social conditions have encouraged greater patient autonomy in dealing with medical issues. In the case of childhood vaccination, patient autonomy comes in the form of parental autonomy as parents are the one who can make decisions with regard to their children medical needs, even if that decision is a refusal to accept medical treatment i.e. vaccination (Asari et al.,2018). Among the reasons for parents refusal are due to their fear that the vaccine is not effective, a desire to avoid exposure to certain chemicals contained in a vaccine; allergies to components of a vaccine; medical conditions that make immunization inadvisable; religious prohibitions; or belief that children should build up their own immune systems by being exposed to illness rather than protected from it. Some of these reasons are based upon personal beliefs, but others are the result of anti-vaccine campaigns which assert 


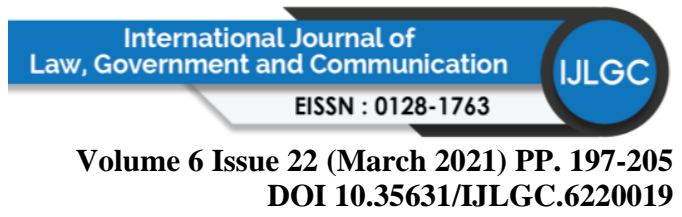

that vaccines are dangerous and those concerns are relayed to parents via the news media and the internet (Winsten \& Serazin, 2013, McKee \& Bohannon, 2016).

Dworkin in his book "Taking Rights Seriously" defends a liberal theory of law, in which he supports the idea that individuals can have rights against the state that are prior to the rights created by explicit legislation. He supports his assertion by appealing to the concepts of human dignity and political equality. According to him, rights are claims against the state which prevent individual needs and preferences from being sacrificed simply on the basis of the collective welfare. The rights of individuals must be taken into account (Dworkin, 1977). This view seems to support parental autonomy in deciding whether to allow vaccination for their children.

\section{Ethical Considerations in Childhood Vaccination}

With regard to the rights of parents to consent on behalf of their children, under the common law parental consent should be secured for children incapable of having a full understanding of the consequences of a particular treatment. In deciding whether to give or refuse consent for treatment, parents must first give primacy to the best interest of the child, failing which the court's approval should be sought. In this regard, the court is taking a paternalistic approach in deciding in favour of the child's best interest (Marion's case, 1992).

Secondly, ethical considerations include whether these parents must take into consideration social responsibility and how their choices in refusing vaccination for their children can affect the health of others. In other words, there should be a balance between respecting parents' autonomy to decide and maximizing the greater good of childhood vaccination through herd immunity. At the same time, there should also be a responsibility on behalf of practitioners, policymakers, and researchers to be empathetic to the rationale underlying parents' decision to refuse vaccination (Hendrix et al., 2016a). For example, in resource-limited settings, a complete infrastructure to offer childhood vaccination may not exist, or parents may not have the opportunities to receive vaccines for their children.

Another ethical consideration is on the issue of distributive justice, where everyone who is able should bear the burden of vaccination to receive the benefit of being protected from the spread of vaccine preventable diseases through herd immunity (Hendrix et al., 2016b). Some legal scholars argue that, under tort remedy, as long as causality can be demonstrated, there is a potential for recourse to hold non vaccinators responsible should their failure to vaccinate lead to infecting others (Reiss, 2014). In justifying the reason to impose liability on parents who choose not to vaccinate their children, these scholars described the parents as 'free-riders; they take advantage of the benefit created by the participation of others in the vaccination program but at the same time they refused to participate and share the risks and obligations of the program. This act of pursuing self-interest and ignoring civic responsibility is an unfair act to other in the community. Even if the law do not punish them, they remain morally liable for their act (Diekema, 2009).

Lastly, ethical issues also bring about the need for research on how best to communicate with parents who refuse vaccination for their children. For example, taking a "presumptive" approach where the doctor assumes the family will agree to recommended vaccinations results in higher rates of vaccination uptake than with a "participatory" approach, where the doctor 


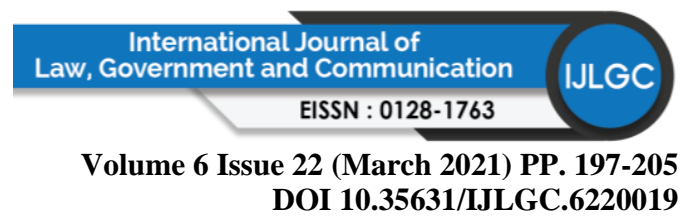

makes no such assumption and asks for the parents' input on whether to vaccinate (Hendrix et al., 2016c).

\section{Childhood Vaccination in Malaysia}

The National Immunisation Programme (NIP) in Malaysia has been introduced since the early 1950s. It is included in the Maternal \& Child Health Programmes under the Malaysian Ministry of Health $(\mathrm{MOH})$, where vaccination is given free under the NIP for all children. From 2015 onwards, non-Malaysian had to pay a minimal fee for vaccination. The NIP protects Malaysian children against 12 major childhood diseases, which are as follows:

a) Diphtheria, an infectious disease caused by bacteria that live in the mouth and throat of the infected person;

b) Haemophilus influenza type B (HIB), a serious infection that mainly affects children under 5 years;

c) Hepatitis B, an infection of the liver by the Hepatitis B virus;

d) Human papillomavirus (HPV), the most common sexually transmitted infection (STI) that causes cervical cancer which is the third most common cancer in women;

e) Japanese encephalitis (JE), an infection of the brain caused by JE virus;

f) Measles, a highly contagious viral disease;

g) Mumps, a viral infection that is the most common cause of inflammation of the brain (encephalitis);

h) Pertussis (Whooping Cough), highly contagious, with violent and persistent coughing that may cause a child to struggle to breathe and, turn blue (cyanosed).

i) Poliomyelitis (polio), an infectious and incurable viral disease that attacks the nervous system;

j) Rubella, also known as German measles that may cause abnormalities to the fetus;

k) Tetanus, also known as lockjaw, caused by bacteria toxins that attacks the body's nervous system; and

1) Tuberculosis (TB), a disease that commonly infects the lungs, but can also attack other parts such as the kidney, spine, skin, intestines and brain.

The MOH gives free vaccination for non-Malaysian during outreach programme, mopping-up activities and supplementary immunisation activities. Aside from free vaccination given at government health facilities, few vaccines are delivered through School Health Service:

i. $\quad 7$ year old: MR, DT, TOPV(stopped), BCG revacc(stopped).

ii. 13 year old: HPV.

iii. $\quad 15$ year old: Tetanus (Kusnin, 2017a).

However, this NIP works only as a clinical immunisation guideline, not legally enforced. The objective of this guideline is to aid healthcare providers in general practice and paediatricians in clinical decision making by providing well balanced evidence based information on childhood immunization with the hope that this guideline can decrease the incident of complications in Malaysia. Aside from this, in curbing the issue of vaccination refusal the MOH has also spearheaded an initiative known as National Immunisation Promotion Campaign 2016-2020. This campaign has specifically three objectives which are, first, to clarify rumours and allegations on vaccines safety. Secondly, to gain community support for 
the National Immunisation Program and for the community to reject anti-vaccination movement. Lastly, the objective of this campaign is to promote and educate parents on vaccination (Kusnin, 2017b).

According to Syed Nokman (2017), Pillay (2016), Kaur (2016) and Augustin (2019), among the reasons for refusals reported are as follows:
i. Halal or haram issue;
ii. Content of vaccination;
iii. Resorting to homeopathy;
iv. Internet influence;
v. Family influence;
vi. Adverse event;
vii. Traditional medicine,
viii. Low risks of getting infection;
ix. Fee; and
x. Other reasons.

In a study done in 2019, six personal health beliefs were identified to be the reason for parents' refusal for vaccination, namely lack of confidence in modern medicine and health care personnel, pharmaceutical conspiracy to sell medicines, preference to a natural approach to health, personal instincts, religious beliefs and having a partner with similar beliefs. Four main vaccine-related concerns were also identified, namely negative effects and content concerns, doubts of necessity and lack of information and knowledge regarding vaccines. In the same study as well parents expressed that communication and empathy from healthcare professionals was lacking (Rumetta et al., 2019).

With regard to doctor-patient relationship in Malaysia, there have been efforts to shift from the traditional medical paternalism to patient-centered model. This model called shared decision making (SDM) is a relatively new concept and not widespread as local research was only initiated around 2010-2011. In 2001, the Malaysian Medical Council has published a guideline on duties of a doctor, which states that the relationship between a doctor and a patient should be "collaborative" and they should be in a "partnership" (Lee \& Ng, 2017). Furthermore, according to Jahn Kassim in 2014, medical decision making should not be a purely medical judgment but a combined opinion between the doctor and the patient. By a process of shared decision-making, autonomous medical choices are usually enhanced rather than undermined. In relation to childhood vaccination, this model paves the way for frank discussion in which a parent's needs and preferences and a doctor's clinical expertise are shared to decide the best decision for the children.

As of date, Malaysia has no specific legislation that renders childhood vaccination compulsory for all. Thus, parents in Malaysia are free to reject vaccination for their children without the worry of facing punishments. It is submitted that the existence of a specific legal framework relating to childhood vaccination will make it easier for the government to take appropriate actions against parents who reject vaccinations based on unjustified reasons.

\section{Conclusion}

In modern health care scenario, the traditional medical paternalistic approach may no longer always be relevant. Patients (parents) nowadays no longer want to be treated as passive 


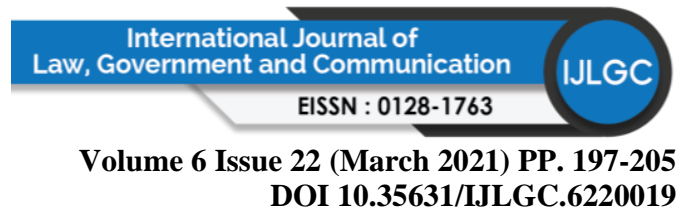

recipients of medical care. Instead, they want to be treated as co-producers or partners able to manage their illnesses (Jahn Kassim, 2009). Furthermore, the current trend of the court is to attach greater importance to the principle of patient's self-determination as it is the right of every human being to make decisions to affect his own life and welfare and to decide on what risks he is willing to undertake (Rogers v Whitaker, 1992). However, the current research is different as it involves parents deciding on behalf of their children. In this regard, the children's best interest should always be the paramount consideration. Thus, it may be reasonable to override a parental refusal if there is a great risk of harm to the child. As children are the future generations of the country, it is highly crucial for the Malaysian government to address this issue seriously, by enforcing compulsory legislation on childhood vaccination. Seeing that the Malaysian government has put in a lot of effort in encouraging childhood vaccination yet the vaccine refusal cases are still on the rise, it is time for punishment to be carried out towards parents. Perhaps when faced with punishment, parents will submit to vaccinating their children.

Nevertheless, in ensuring success of the proposed legal framework on compulsory childhood vaccination in Malaysia, certain ethical considerations should be practiced. For instance, by ensuring that there is a balanced harmony between medical paternalism and parental autonomy in childhood vaccination decision making. This can be seen in the new patient-centered model or shared decision making between doctors and parents when it comes to deciding on childhood vaccination. Furthermore, doctors, policymakers and researchers should have more empathy in understanding the reasons behind parents' refusal to vaccinate their children. This will help in improving communication between doctors and parents. Example can be taken from the US vaccination laws which allows exemptions in terms of medical, religious or personal beliefs reasons. At the same time, the government should focus more on educating parents on childhood vaccination to ensure that they will not depend on misinformation that can be easily available online.

In conclusion, the discussion in this paper is important as it stimulates further research on issue of compulsory childhood vaccination in Malaysia. Since existing studies in Malaysia on childhood vaccination mainly focuses on the reasons for vaccine refusal by parents, this study which focuses on the legal and ethical perspective of compulsory childhood vaccination clearly bridges the gaps in existing studies in Malaysia. The findings of this study will also assist the policy makers namely the Malaysian Government, Ministry of Health, and other stakeholders in ensuring that both legal and policy responses are properly applied in addressing specific problems in enforcing compulsory childhood vaccination.

\section{References}

Aharon A.A., Nehama, H., Rishpon, S. and Bron-Epel, O., (2017). Autonomy and control among parents who do not comply with recommended pediatric vaccinations: A qualitative case study. Journal of Community and Public Health Nursing, 3, 1-6. doi:10.4172/2471-9846.1000152

Arumugam, T. (2019, December 10). Paediatrician: Anti-vaccination group endangering kids' lives. The New Straits Times. Retrieved from https://www.nst.com.my/news/nation/2019/12/546496/paediatrician-anti-vaccinationgroup-endangering-kids-lives

Asari, K. N., Makhtar, M., Abdullah Asuhaimi, F \& Pauzai, N. A. (2018). Compulsory childhood vaccination in malaysia: Public health versus parental autonomy. 


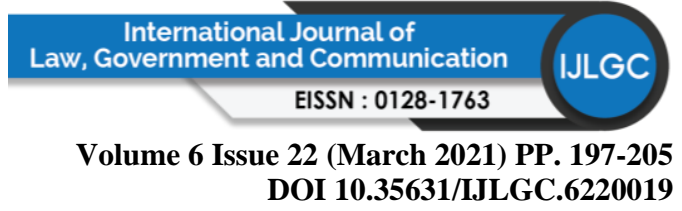

International Journal of Academic Research in Business and Social Sciences, 8 (12), 1540-1548. doi: 10.6007/IJARBSS/v8-i12/5256.

Augustin, R. (2019, January 24). Myth busters out to give antidote to anti-vaccine arguments. Free Malaysia Today News. Retrieved from https://www.freemalaysiatoday.com/category/nation/2019/01/24/from-halal-status-toconspiracy-theories-docs-take-anti-vaxxers-head-on/

Baxter, T. D. (2014). Tort liability for parents who choose not to vaccinate their children and whose unvaccinated children infect others. University of Cincinnati Law Review, 82 (1), 103-144.

Bowie, N. E. (1977). Taking rights seriously. By Ronald Dworkin. Massachusetts: Harvard University Press. California University Law Review, 26, 563.

Chephra, M. \& Bohannon, K. (2016). Exploring the reasons behind parental refusal of vaccines. The Journal of Pediatric Pharmacology and Therapeutics 21 (2), 104-109.

Chung, C. (2019, December 8). Polio case reported in Malaysia - first in 27 years. The Star Online, Retrieved from https://www.thestar.com.my/news/nation/2019/12/08/poliocase-reported-in-malaysia--first-in-27-years

Diekema, D. S. (2009). Choices should have consequences: Failure to vaccinate, harm to others, and civil liability. Michigan Law Review First Impressions, 107, 90-94. http://repository.law.umich.edu/mlr_fi/vol107/iss1/12.

Hendrix, K. S., Sturm, L. A., Zimet, G. D., \& Meslin, E. M. (2016). Ethics and childhood vaccination policy in the united states. American Journal of Public Health, 106 (2), 273-278. https://doi.org/10.2105/AJPH.2015.302952.

Immunisation Schedule. (2019). Retrieved December 2, 2019 from http://www.myhealth.gov.my/en/immunisation-schedule/.

Jackson, C. L. (1969). State laws on compulsory immunisation in the united states. Public Health Reports, 84 (9), 787-796.

Jacobson v. Massachusetts. (1905), 197 U.S. 11.

Jahn Kassim, P. N. (2009). Medical Negligence in Malaysia: Cases and Commentaries. Selangor: Sweet \& Maxwell Asia.

Jahn Kassim, P. N. (2014). The growth of patient autonomy in modern medical practice and the defined limitations under the sharī'ah. IIUM Law Journal, 22(2). https://doi.org/10.31436/iiumlj.v22i2.135

Kusnin, F. (2017). Immunisation Programme in Malaysia. Paper presented in Vaccinology 2017 the 3rd International Symposium For Asia Pacific Experts, Vietnam, 16-19 October 2017. Retrieved from https://www.fondation-merieux.org/wpcontent/uploads/2017/10/vaccinology-2017-faridahkusnin.pdf\#page=23\&zoom=auto,239,503

Kaur, M. (2016, September 2). Anti-vaccine groups on the rise. The Star Online. Retrieved from https://www.thestar.com.my/metro/community/2016/09/02/antivaccine-groupson-the-rise-preventable-diseases-on-the-increase-for-children-in-malaysia-because/

Lee, Y. K., \& Ng, C. J. (2017). The state of shared decision making in Malaysia. Zeitschrift fur Evidenz, Fortbildung und Qualitat im Gesundheitswesen, 123-124, 66-68. doi: 10.1016/j.zefq.2017.05.019.

McCoy, M. (2008). Autonomy, consent, and medical paternalism: Legal issues in medical intervention. The Journal of Alternative and Complementary Medicine, 14 (6), 785792. doi: 10.1089/acm.2007.0803.

Mill, J. S. (2010). On Liberty. London: Penguin. 
Minister ready to consider making two of 12 vaccines compulsory. (2019, March 7). Borneo Post Online, Retrieved from https://www.theborneopost.com/2019/03/07/ministryready-to-consider-making-two-of-12-vaccines-compulsory/.

Pillay, S. (2016, January 17). The vaccination dilemma. The New Straits Times. Retrieved from https://www.nst.com.my/news/2016/01/122580/ vaccination-dilemma.

Reiss, D.R. (2014). Compensating the victims of failure to vaccinate: What are the options?. Cornell Journal of Law and Public Policy, 23, 595-633. https://papers.ssrn.com/sol3/papers.cfm?abstract_id=2317548.

Rogers $v$ Whitaker (1992) HCA 8-175 CLR 479.

Rumetta, J., Abdul Hadi, H. \& Lee, Y. K. (2020). A qualitative study on parents' reasons and recommendations for childhood vaccination refusal in Malaysia. Journal of Infection and Public Health, 13 (2), 199-203. https://doi.org/10.1016/j.jiph.2019.07.027.

Secretary of State for Health \& Community Services v JW (Marion's case) (1992) 175 CLR 218

Sporton, R.K. \& Francis, S. A. (2001). Choosing not to immunize: are parents making informed decisions? Family Practice, 18 (2), 181-188, https://doi.org/10.1093/fampra/18.2.181

Syed Nokman, F. (2017, April 11). Puzzled by parents' anti-vaccine stand. The New Straits Times. https://www.nst.com.my/news/nation/2017/04/229369/\%20puzzled-parents-antivaccine-stand.

Winsten, J. \& Serazin, E. (2013).Rolling back the war on vaccines. Wall Street Journal 15, Retrieved from http://online.wsj.com/article/SB100014241278873240395045782602 42982589914.html. 